\title{
Educational Human Resource Projection: A Study in Vietnamese Preschool Education from 2017 to 2027
}

\author{
Van-Son Huynh', Thien-Vu Giang ${ }^{2, *}$, Vinh-Loc Sam ${ }^{3}$, Luong Tran ${ }^{4}$, Vinh-Khuong Nguyen ${ }^{5}$ \\ ${ }^{1}$ Vice Rector, Ho Chi Minh City University of Education, Ho Chi Minh City, Vietnam \\ ${ }^{2}$ Department of Psychology, Ho Chi Minh City University of Education, Ho Chi Minh City, Vietnam \\ ${ }^{3}$ Department of Physical Education, Ho Chi Minh City University of Education, Ho Chi Minh City, Vietnam \\ ${ }^{4}$ Department of Pedagogy, Can Tho University, Can Tho City, Vietnam \\ ${ }^{5}$ Department of Technology and Science, Ho Chi Minh City University of Education, Ho Chi Minh City, Vietnam
}

Received March 12, 2020; Revised April 9, 2020; Accepted April 27, 2020

Copyright $\bigcirc 2020$ by authors, all rights reserved. Authors agree that this article remains permanently open access under the terms of the Creative Commons Attribution License 4.0 International License

\begin{abstract}
Projecting the demand for teacher training is supposed to be regularly implemented to ensure the sustainable development of a country's education. Preschool education is the first level of education in the national education system with the specific requirements on professionalism as well as the labor characteristics of preschool teachers. The goal of this study is to apply projection equations based on understanding the situation of the Vietnamese preschool teachers as well as the number of graduates, retired teachers, and the number of children to acquire the projection results of the preschool teachers needed for Vietnam in the period 2017 - 2027. The results indicated that the current preschool teachers did not meet the requirements of the education system in terms of quantity. This deficiency might be likely to last for the next ten years and cause many consequences for Vietnamese education if there were no solutions to human educational resources. The result of the projection problem in Vietnam was an experience lesson that should be considered in Asia with distinctive socio-cultural characteristics.
\end{abstract}

Keywords Educational Projection, Educational Human Resource Projection, Teacher Training Demand, Preschool Teacher, Preschool Education

\section{Introduction}

Human resources of a country are significant in which the human educational resources - national policy in Vietnam plays a vital role [1]. In education, there are many issues which need to be addressed from the goals, the contents of the program, the educational and training methods, the management mechanisms, and the policy systems to mobilize resources for the educational development, especially the problems of the development of the teaching staff and the educational managers - an important factor directly affecting the quality of education and training in Vietnam. In the context that Vietnam is facing new opportunities and challenges in improving the academic programs, the teachers and the educational managers are required to be the fundamental forces to decide the successful implementation of the goals of the educational strategy. It can be affirmed that the preparation of the teaching staff with basic and well-qualified qualifications for their professional career is an urgent requirement not only for the education sector but also for the whole nation.

The human educational resources and the teacher system directly affected the quality of the education [2-4]. Indeed, at each educational level, the influence of the teachers could be different. However, it is undeniable that the teachers create important marks in national education. The projection theory on education demands to be allowed to make the predictions to prepare the teaching staff to meet the practical demand [5]. The issue of the active development of the teaching staff needs to be recognized on many criteria with a substantial base, the teacher training and developing capacity of the institution, the real demand of the education sector as well as the demand and the expectations of the students' parents, the school administrators, and the educational development orientations as the considered requirements to lead the development of the human resource for Vietnamese education.

In particular, for the Vietnam Department of Education and Training as well as the Teacher Education Institutions, these are the essential data to guide the tasks, developing and training targets as well as the strategic issues. This showed that the projection of the teacher training demand is an essential and urgent mission, especially in the context 
of today's education innovation.

Preschool education was the first level of the national education system in which it is necessarily considered in the world [6-8]. The preschool teachers (PT), which violated the educational regulations as well as transferred their career at preschool education, had affected this level of education in Vietnam. According to the report of the Ministry of Education and Training, the development scale of the preschool education was uneven in the regions in Vietnam; the quality of the preschool education was not stable; the network of the preschool education policies was not synchronized, and the investment resources for this education level was the lowest in the sector [9]. Therefore, the system of infrastructure to the teaching career has not met the education's demand. Meanwhile, this was the most cost level because the state expenditure ratio accounted only for $39 \%$. Each year, the number of preschool children increased by 250,000 , which was under considerable pressure on schools and teachers [10]. Based on the educational regulations, each standardized preschool class should reach the lowest rate of 2.2 teachers (approximately 2 teachers per class). However, in fact, in many provinces and cities, this figure was only limited to 1.5 to 1.8 teachers (approximately 2 classes have 3 teachers). The current source of teachers was lacking; the number of children continuously increased while the PT recruitment and retention were challenging to do because this career was under high pressure and low income. Currently, Vietnam lacked more than 33,000 PT. If the shortage of teachers were prolonged, it would affect the quality of education and quickly cause an unsafe situation for preschool children.

Based on the situation of Vietnamese preschool education, the projection of teacher training demands as well as the number of the PT needed for the preschool education in the following years (2017 - 2027), especially in the period of the implementation of the new general academic program (start from 2020), was as the necessary and urgent solution which would be used to solve the existing Vietnamese educational human resource problems.

\section{Literature Review}

Educational projection (EP) is to determine the future state of the educational system with a certain probability. EP is an essential basis in developing human educational resources [10]. Projecting the teacher training demands is one of the primary contents of the EP. The EP serves the management and educational managers to have a scientific and practical basis for making feasible short-term, medium-term, and long-term plans [11]. EP contributes to establishing optimal plans, identifying trends in the development of goals to be used as a basis for the formulation of strategic plans for educators to control and adjust in planning a science-based education strategy [12]. $\mathrm{EP}$ also contributes to building and promoting the vision of an individual in education [13]. At the same time, to ensure forceful EP, managers once again need to do their best in their assigned positions. Each individual or team leader, and especially the manager, demand to consider the skills of projecting and practices so that they can perfect themselves to better handle what happens in the professional [14]. For educational managers, EP allows them to analyze the situation, understand the causes, and make educational decisions that contain educational solutions or measures to synchronize and meet practical demand [15]. Some commonly used EP methods include:

The Delphi Method: The Delphi Method is an enhancement of the expert council (collective) method. The Delphi method was adopted by a group of US experts from RAND and was first published in 1964 [16]. The Delphi method allows generalizing the opinions of individual experts to the general opinion of the expert group. Experts have highly appreciated the Delphi method because it is relatively simple to apply and can be used even by non-experts. However, it has weaknesses; it gives a list of likely innovations but not to show the relationship between these innovations. This method is applied in the technique of projection the number of children attending school.

Expert method: An expert method is a method based on the opinions of many people with expertise in the field is projected (like Delphi method). This method is considered a useful tool to project the problems to the scale of education and training, and related factors in different fields but cannot be explicitly calculated [17]. The expert method is particularly useful in the following cases:

- When the projecting object has high coverage, it depends on many factors that currently do not yet have or lack theoretical bases to determine.

- In the absence of sufficient information and reliable statistics on the characteristics of the projecting object, it is not allowed to use the correct scientific method to solve the projecting problem.

- In the condition of high uncertainty projecting object, low reliability in the form of expression, the direction of variation in scope as well as scale and structure.

- In the absence of time, urgent circumstances of the expert method are also applied to make a timely projection.

- Due to lack of time or due to urgent circumstances requiring projection to be met or solved within the time limits allowed.

- When projecting the medium and long term, the projecting objects are influenced by many factors, most of which are difficult to quantify, especially those of psychosocial factors (education, tastes, habits, lifestyles, population characteristics) or scientific and technical advances. Therefore, the projecting object has many mutations in size and structure without which, thanks to the expertise of experts, everything becomes meaningless.

Extrapolation method: This method brings together a 
group of experts considered intuition thanks to the technical capital of imagination itself or deduction of future industrial or social innovations and industrial development or expressed demand. Extrapolation methods are the most commonly used methods in quantitative projections or general projections and projection based on a quantitative basis [18-20]. The weakness of this method is that the debate among experts can adversely affect more accurately but minority estimate and favor false projections that are universally agreed upon. Steps to implement the extrapolation method according to the trend function to project the number of students attending school:

Step 1: Make a statistic of the number of students that need to be projected in the years before the time of projecting and calculate the percentage of students attending school in the age group.

Step 2: Based on the number of students attending to school in previous years, determining the trend of developing the rate of students attending to school with time and using extrapolation method according to the trend function determined in the past to calculate the rate of students attend to school for projected years.

Step 3: Calculate the rate of future students based on the trend function and population projection in age to infer the number of students attending school each year in the future.

Correlation method: Correlation method is a projection method that helps to detect the changing trend of the research phenomenon about one or several other factors based on past statistical observations and from which thinking for the future [21].

The following steps need to be performed in this method:

Step 1: Identity projecting objects.

Step 2: Select the influencing factors.

Step 3: Collect data and process data according to the technical requirements of the plan.

Step 4: Determine the correlation function.

Step 5: Calculate projections.

Short term load forecasting: This projecting method is processed based on a standard norm or ideal norm or assumed norm for a specific and specific standard [22]. This projection method is usually used for the number of teachers per class or the number of students a teacher is in charge of or the number of teachers required to have a specific job and arithmetic norm.

Specific steps can be mentioned in the EP process as follows: (1) Determine the projecting time marks; (2) Determine the current state; (3) Identify the future time marks; (4) Determine the projecting framework; (5) Determine the projecting plans and projecting models; (6) Determine the future state; (7) Define the official projecting data []. The EP process can be conducted projecting many different contents. However, in the world and Vietnam, the EP process is often carried out in the task of projecting resources, most clearly projecting the human resources of teachers and students. In this study, the researchers applied the projecting process to conduct a project of the number of PT needed for Vietnamese education for over ten years. Specific EP methods are presented in the next section.

\section{Methodology}

\subsection{Study Design and Instruments}

Teacher training demand projection is a projection of the development scale, training quality, the structure of the current teachers to make a proposal that requires development scale, training quality, and the structure of the teaching staff demand to be met and demand to be trained in a specific schedule. Therefore, in this study, projecting the PT training demands need to perform the following tasks:

- Determine the current situation of the development scale, the quality of training, the structure of the teaching staff through the current time points.

- $\quad$ Build the establishments with projecting changes to conduct the projection of change and development of the situation of teachers in the future:

- The number of teachers retiring, transferring the career

- Standard regulations on the number of standard hours of teachers

- New requirements of society and national education.

- The workload of PT.

This is a quantitative study, which uses the extrapolation method based on data provided and officially transferred to the study project. It is the data to survey the situation of preschool teachers in the provinces of Vietnam, which are transferred both original and reference data. After that, the research team read and conducted internal research. The data will be analyzed in the initial test, compared with the data and the data with the same scale (Results of an analysis of Vietnam's educational situation by international organizations, the Yearbook of the Vietnamese People published on the mass media, Annual report of Vietnamese Ministry of Education and Training).

\subsubsection{The Projecting Equation of the Preschool Teacher Training Demand (Equation 1)}

Step 1: Find the total number of current preschool teachers $\left(\mathrm{N}_{\mathrm{PT}}\right)$

Step 2: Find the number of preschool teachers going to retire and transfer the career $\left(\mathrm{N}_{\mathrm{RPT}}\right)$

Step 3: Find the number of children attending primary school (6 years old) $\left(\mathrm{N}_{6 y o}\right)$

Step 4: Find the number of children attending to the first preschool-grade (3 years old, $\mathrm{N}_{3 y \mathrm{yo}}$ ), the middle preschool-grade (4 years old, $\left.\mathrm{N}_{4 y o}\right)$ and the last preschool-grade ( 5 years old, $\mathrm{N}_{5 \mathrm{yo}}$ ) 
Step 5: Find the current number of preschool children (A):

$$
A=\mathrm{N}_{3 \mathrm{yo}}+\mathrm{N}_{4 \mathrm{yo}}+\mathrm{N}_{5 \mathrm{yo}}+\text { the children preparing to enter the first preschool year }-\mathrm{N}_{6 \mathrm{yo}}
$$

Step 6: Using the result in step 5 to continue to find the needed preschool teachers (B) in one academic year:

$$
\boldsymbol{B}=\frac{A}{\text { the standardized number of teachers per class regulated by the MOET }}-\mathrm{N}_{\mathrm{PT}}-\mathrm{N}_{\mathrm{RPT}}
$$

Step 7: Create a table of data (B value) in the form of the total each year

\subsubsection{Projecting the Teacher Suppliers (Shortage or Redundancy, Equation 2)}

Step 1: Find the number of undergraduate preschool children each academic year $\left(\mathrm{N}_{\mathrm{Sx}}, \mathrm{x}\right.$ is the academic-year level of the first preschool-grade children, e.g., $\mathrm{N}_{\mathrm{S} 1}-$ the number of the middle preschool-grade children, $\mathrm{N}_{\mathrm{S} 3}-$ the number of the last preschool-grade children).

Step 2: Find the number of senior preschool education undergraduate students graduated each year from pedagogical universities and colleges $\left(\mathrm{N}_{\mathrm{S} 4}\right)$

Step 3: Perform the equation below to find the teacher suppliers (C) (shortage - negative or redundancy positive)

$$
\mathrm{C}=\mathrm{B}-\mathrm{N}_{\mathrm{S} 4}
$$

Step 4: Projecting the following years based on the gradual development of the number of the preschool teachers / each grade is missing in part a (B value) and the number of the children in years 1,2,3 trained for each level $\left(\mathrm{N}_{\mathrm{S} 1}, \mathrm{~N}_{\mathrm{S} 2}, \mathrm{~N}_{\mathrm{S} 3}\right)$. Projecting with data for the next years by advancing the data of the previous year for the following year.

\subsection{Participants}

All the number of the current PT in public and private preschools (data from the Departments of Education and Training of each province) in 32/64 provinces and cities were collected and presented as participants from Da Nang to Ca Mau: Da Nang, Quang Nam, Quang Ngai, Gia Lai, Kon Tum, Dak Lak, Dak Nong, Lam Dong, Binh Dinh, Phu Yen, Khanh Hoa, Ninh Thuan, Binh Thuan, Ho Chi Minh City, Ba Ria - Vung Tau, Binh Duong, Binh Phuoc, Dong Nai, Tien Giang, Long An, Vinh Long, Dong Thap, Tra Vinh, Can Tho, Soc Trang, Bac Lieu, Ca Mau, Hau Giang, An Giang, Kien Giang, Tay Ninh, Ben Tre.

According to Nguyen's study (1996), the population projection conducted on the sample size from $1 / 2$ provinces and cities in the whole country is statistically significant [23]. Therefore, the projection with $50 \%$ of the population (preschool teachers) from 32 provinces and cities of Vietnam was reliable and meaningful.

\subsection{Data Analysis}

To process the collected data, the researcher used SPSS software version 20.0 to process data about the frequency and ratio of PT numbers and, the formula format to calculate the number of PT differences over the years (the number of PT out of the professional and start working). The analysis and discussions are conducted based on the output data of the projecting formulas which have been established.

\section{Results}

\subsection{Investigating the Situation of the Recent Vietnamese Preschool Teachers}

To have enough data for the projection equation of the number of PT in the period of 2017 - 2027, the situation of the PT staff was investigated. The results were presented in Table $1\left(\mathrm{~N}_{\mathrm{PT}}\right.$ and $\mathrm{N}_{\mathrm{RPT}}$ in Equation 1).

Table 1. The current number of preschool teachers

\begin{tabular}{|c|c|c|c|c|c|c|}
\hline \multirow{2}{*}{$\begin{array}{c}\text { Academic } \\
\text { years }\end{array}$} & \multicolumn{4}{|c|}{ The number of preschool teachers } \\
\cline { 2 - 7 } & Working & \multicolumn{2}{|c|}{ Retired } & \multicolumn{2}{c|}{$\begin{array}{c}\text { Career } \\
\text { transfer }\end{array}$} \\
\cline { 2 - 7 } & $\mathrm{N}$ & $\%$ & $\mathrm{~N}$ & $\%$ & $\mathrm{~N}$ & $\%$ \\
\hline $2010-2011$ & 101274 & 98.08 & 1314 & 1.27 & 669 & 0.65 \\
\hline $2011-2012$ & 108437 & 98.20 & 1335 & 1.21 & 648 & 0.59 \\
\hline $2012-2013$ & 110923 & 98.24 & 1244 & 1.10 & 748 & 0.66 \\
\hline $2013-2014$ & 112808 & 98.24 & 1373 & 1.20 & 650 & 0.57 \\
\hline $2014-2015$ & 114903 & 97.98 & 1624 & 1.39 & 741 & 0.63 \\
\hline
\end{tabular}

The results showed that there was an increase of 13,629 PT from 2010 to 2015 in general. More specifically, the number of the teachers could increase gradually in each period: in 2010-2011, it was increased with 101,274 teachers; until 2011-2012, the number of the teachers was increased with 108,437 , increasing by 7,163 teachers, equivalent to $7.07 \%$. In $2012-2013$, it was 110,923 , increasing by 2,486 , equivalent to $2.29 \%$ compared to 2011-2012, equivalent to the rate of the retired teachers. In 2013-2014, the PT was reached at 112,898 , increasing by 1,885 , equivalent to $1.7 \%$ compared to $2012-2013$. This data showed that the number of PT increased, but the trend was decreasing. Finally, in 2014-2015, there was an increase of 2,095 with a percentage of $1.86 \%$ compared to 2013-2014. In other words, in this period, the number of PT increased more slowly than the previous year. 
Table 2. The situation of the preschool teacher shortage and redundancy

\begin{tabular}{|c|c|c|c|c|c|}
\hline $\begin{array}{c}\text { Academic } \\
\text { years }\end{array}$ & $\begin{array}{c}\text { The increase in the number } \\
\text { of children compared to the } \\
\text { previous year }\end{array}$ & $\begin{array}{c}\text { The number of } \\
\text { PT needed to } \\
\text { recruit }\end{array}$ & $\begin{array}{c}\text { The transferred } \\
\text { and retired PT }\end{array}$ & $\begin{array}{c}\text { The number of } \\
\text { recruited } \\
\text { teachers }\end{array}$ & $\begin{array}{c}\text { The number of teacher } \\
\text { shortage }(-) \text { and the teacher } \\
\text { redundancy }(+)\end{array}$ \\
\hline $2011-2012$ & 93551 & 6237 & 1983 & 7163 & +926 \\
\hline $2012-2013$ & -848 & -34 & 1992 & 2486 & +2520 \\
\hline $2013-2014$ & 32909 & 1317 & 2023 & 1885 & +568 \\
\hline $2014-2015$ & 1193 & 48 & 2365 & 2095 & +2047 \\
\hline
\end{tabular}

(only based on the number of the children of increase compared to the additional recruitment of the PT)

In terms of the retired PT, the number of this group fluctuated in each period. Specifically, in 2010-2011, there were 1,314 retired teachers, and in 2011-2012 there were 1,335 retired teachers. There was an increase of 21 retired teachers in this period, corresponding to an increase of $1.6 \%$. In 2012-2013, there were 1,244 retired teachers, a decrease of 91 retired teachers compared to 2011-2012, corresponding to an increase of $6.82 \%$ (4 times higher than the previous academic year). In 2013-2014, 1,373 teachers retired, compared to the period of 2012-2013 corresponding to $10.3 \%$, this was a prominent figure for the recruitment of the new teachers. In 2014-2015, there were 1,624 retired teachers, and the number of retired teachers highly increased with 251 retired teachers, compared to 2013-2014, equivalent to $18.28 \%$. It was able to be seen that the PT tended to increase in retiring in recent years gradually. This showed the problems in training and recruiting teachers so that there could be the PT forces for timely replacement.

Based on the total number of the transferred and retired teachers as well as the number of children increasing each year, the data could be generalized in Table 2 (applied Equation 2).

The number of teachers who changed their jobs also fluctuated erratically in each period, specifically: Until 2011-2012, 648 teachers were transferring their jobs. In 2012-2013, 748 teachers were changing their jobs, an increase of $15.43 \%$ compared to $2011-2012$. Next, in 2013-2014, 650 teachers were changing their jobs. In this academic year, the number decreased by 98 teachers corresponding to $13.1 \%$ compared to the period of 2012-2013. Finally, in 2014-2015, 741 teachers were moving to other jobs, a rise of 91 teachers with a corresponding percentage of $14.0 \%$ compared to the period of 2013-2014.

The data in Table 2 showed that in 2011-2012, there were 1,983 PT retired and transferred. Therefore, it is necessary to recruit about 1,983 teachers to replace the number of retired and transferred teachers. However, it could be realized that between 2011 and 2012, the number of PT rose by 7,163 compared with the one in 2010-2011. It was clear that there was a significant difference $(7,163-$ $1,883=3,420$ teachers). The number of recruited teachers was higher than the number of retired and transferred teachers. In 2012-2013, the total number of the retired and transferred teachers was 1,992 teachers; the number of PT in this academic year increased by 2,486 teachers compared to 2011-2012. The number of recruited teachers continued to be higher than the number of retired and transferred teachers. By 2013-2014, the total number of the retired and transferred teachers was 2,023. The percentage of the teacher increase compared to 2012-2013 was 1,885. In 2014-2015, there were 2,365 PT who retired and transferred their jobs; the number of the additional recruitment of the PT for this period was 2,095 teachers. In both academic years, the number of additional teachers was lower than the number of retired and transferred teachers.

This was clarified more when analyzing the data of 5 years. From 2010 to 2015, the number of teachers increased by 13,629 teachers; the total number of the retired and transferred teachers for five years was 10,346 preschool teachers $(6,890$ retired teachers and 3,456 transferred teachers). Thus, the number of recruited preschool teachers from 2010 to 2015 tended to be more than the number of retired and transferred teachers - not including the increase in the number of children. In fact, from 2010 to 2015, there were additionally 126,798 children. With 126,798 of these children, they needed about 8,454 PT (each teacher was in charge of 15 children).

\subsection{Projecting the Number of Preschool Teachers in the Period 2017 - 2027}

To project the number of the PT needed for the period 2017-2027, it was conducted to examine and project the number of undergraduate students as input and output of the preschool education at the pedagogical universities and colleges in the research scope (from 32 Vietnam provinces). The results were presented in Table 3 (Applied Step 2 in Equation 2):

Table 3. Forecasting the number of undergraduate students as input and output

\begin{tabular}{|c|c|c|c|}
\hline \multirow{7}{*}{$\begin{array}{c}\text { Pedagogical } \\
\text { universities and } \\
\text { colleges }\end{array}$} & Academic years & Input & Output \\
\hline & $2010-2011$ & 3893 & 3271 \\
\hline & $2011-2012$ & 4098 & 3443 \\
\hline & $2012-2013$ & 3903 & 3279 \\
\hline & $2013-2014$ & 4108 & 3452 \\
\hline & $2014-2015$ & 4842 & 4224 \\
\hline & $2015-2016$ & 4552 & 3774 \\
\hline
\end{tabular}


From the data obtained in the next academic years from 2010 to 2016, preschool education accounted for a high proportion of teacher education. The number of students was highly enrolled in universities and colleges in recent years. This data showed that the need for the PT at preschool level was tremendous and tended to increase over the years (although there was a decrease, it was not significant).

The output of preschool education was no exception when in the year 2014-2015 also increasing by 773 graduate students compared to the previous year, corresponding to the rate of $18.3 \%$. However, it immediately fell sharply approximately the same as this rate in 2015-2016 with about 450 graduated students, corresponding to the rate of $11.9 \%$. It could be said that the sharp fluctuations in the number of preschool education undergraduate students resulted from the increase in the student population in the previous years, which caused a significant increase in the number of school-age children. As a result, there was a sharp increase in the need for schools and new teachers also, especially for preschool-age children.

Data in Table 4 showed that the number of preschool children under the projection was increasing steadily (Applied Equation 2, Step 4).

The rise in the number of children was not significant. From 2017 to 2027, the figure ranged from more than $23,500,000$ to the anchor figure of over 2,500,000 children who demonstrated this realization. It was also a change in the actual need of preschool children and its satisfaction quality assurance. If the academic year 2017-2018 was considered as the starting point, it was changed into the percentage of the variation in the number of children who needed to attend school over the years. This variation was relatively complicated. At the preschool level, the level of projected variation was the most erratic. In the first year of the forecast chain, the number of children attending preschool dropped sharply by approximately $1.41 \%$ in 2018-2019. However, after that, the number of children attending preschool was projected to continuously increase for three academic years from 2019 to 2022 , with the rates of $0.2 \%, 2.13 \%$, and $3.35 \%$, respectively. However, it was predicted that this school level would decrease continuously until 2027, with the highest reduction rate of $3.19 \%$ in $2026-2027$.

Table 4. Projecting the need of the preschool children attending school

\begin{tabular}{|c|c|c|}
\hline \multirow{2}{*}{$\begin{array}{c}\text { Academic } \\
\text { year }\end{array}$} & $\begin{array}{c}|c| \\
\text { Number of } \\
\text { children }\end{array}$ & $\begin{array}{c}\text { Number of the standardized } \\
\text { classes }\end{array}$ \\
\hline $2017-2018$ & 2392763 & 79759 \\
\hline $2018-2019$ & 2359394 & 78646 \\
\hline $2019-2020$ & 2364134 & 78804 \\
\hline $2020-2021$ & 2415552 & 80518 \\
\hline $2021-2022$ & 2499209 & 83307 \\
\hline $2022-2023$ & 2488789 & 82960 \\
\hline $2023-2024$ & 2478579 & 82619 \\
\hline $2024-2025$ & 2460072 & 82002 \\
\hline $2025-2026$ & 2435421 & 81181 \\
\hline $2026-2027$ & 2360142 & 78671 \\
\hline
\end{tabular}

Under preparation of data for the PT projection, the number of retired preschool teachers for the period of 2017-2027 was projected, as shown in Figure 1:

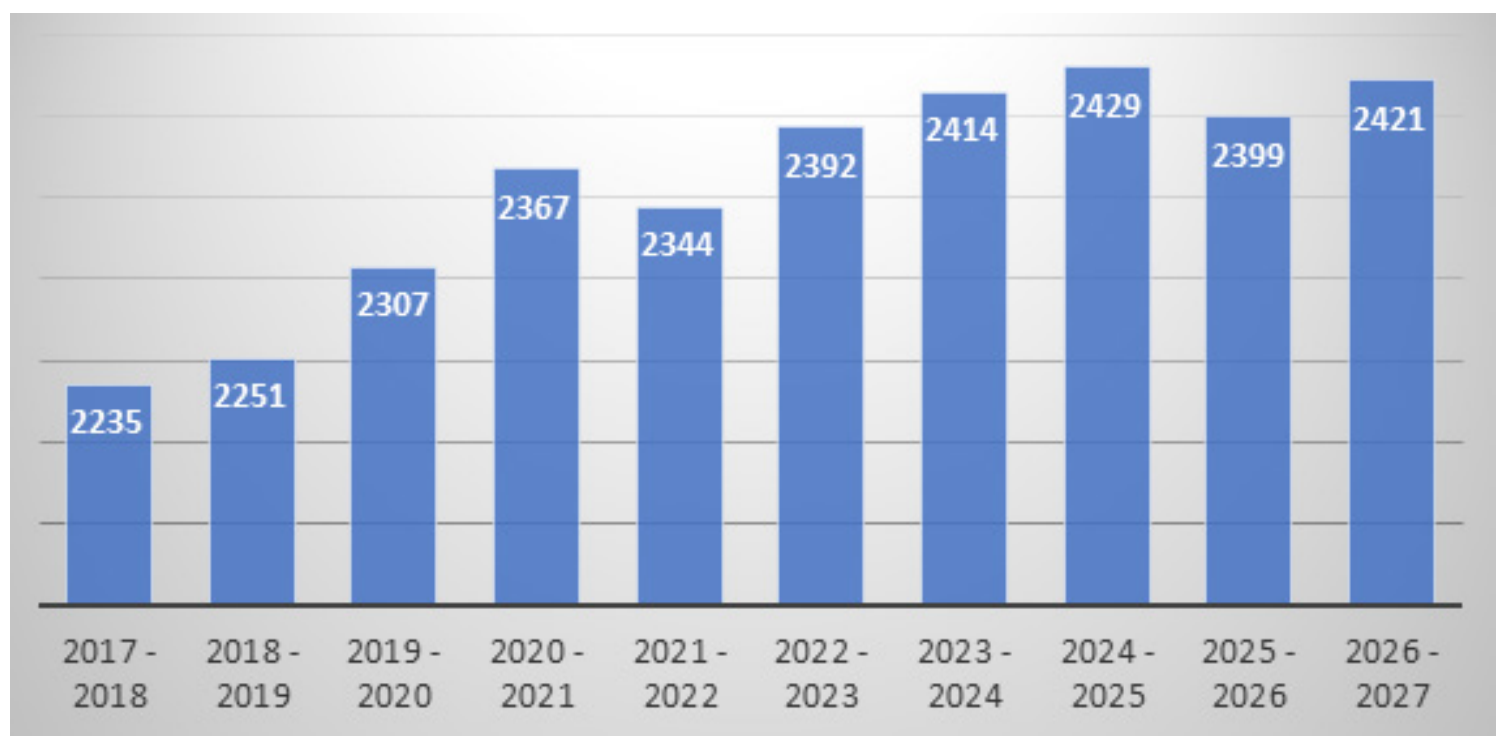

Figure 1. Projecting the retired preschool teachers 
Table 5. Projecting the number of preschool teachers

\begin{tabular}{|c|c|c|c|}
\hline \multirow{2}{*}{ Academic years } & \multicolumn{3}{|c|}{ Preschool education } \\
\cline { 2 - 4 } & The graduated students & Number of the teachers needed under regulations & Sufficiency/shortage \\
\hline $2017-2018$ & 6009 & 175469 & -51201 \\
\hline $2018-2019$ & 6286 & 173022 & -45893 \\
\hline $2019-2020$ & 6564 & 173370 & -43422 \\
\hline $2020-2021$ & 6841 & 177140 & -44425 \\
\hline $2021-2022$ & 7119 & 183275 & -47828 \\
\hline $2022-2023$ & 7396 & 182511 & -44228 \\
\hline $2023-2024$ & 7674 & 181762 & -40644 \\
\hline $2024-2025$ & 7951 & 180405 & -36443 \\
\hline $2025-2026$ & 8229 & 178598 & -31784 \\
\hline $2026-2027$ & 8506 & 173077 & -23356 \\
\hline
\end{tabular}

With the projection figures, the number of PT for ten consecutive years from 2017 to 2027 was insignificant (the highest was 56 teachers - in 2019-2020, the lowest was 22 teachers - in 2023-2024) in general.

Based on data on the situation of the current PT, the projection of the number of the children attending to school, the input and output children of the preschool education, and the projection of the number of the retired PT in the period of 2017-2027, applying the projection formula of the number of the PT needed for this educational level, the result in projecting the number of PT in the period 2017-2027 was showed in Table 5 (Applying the Equation 2 and extrapolation method).

The data in table 5 showed that, based on the current situation of the preschool education, the current teacher assignment type, and school standards, it was easy to see the number of the projected PT was not being provided enough in the next ten years. Specifically, for ten consecutive years, there was a shortage of more than 12,000 teachers to the highest of 25,000 PT. The academic year of the highest shortage of the PT was 2020-2021, with 24,820 teachers. This clearly showed that the need for the $\mathrm{PT}$ in practice was still inadequate, and the chain projection showed that without effective solutions, there would be a risk of long-lasting and sharp shortage in 2022-2023.

Besides, the number of PT had not been enough about 24,314 teachers since 2017. Many different reasons could explain this. The first reason is the fact that the PT in 2016 was still not enough, and this situation lasted until 2017. On the other hand, in 2017, the number of children increased according to the varying cycle, so the lack of PT was somewhat affected.

Analyzing statistics, in the 10-year projection chain, in the first six years, the number of the PT was still lack of over 20,000 people. After that, for four consecutive years, this ratio fell below 20,000 and gradually decreased significantly.

\section{Discussions}

In 2017, with the projection of the number of the children attending to preschool and the situation of the retired PT ranging from $1.2 \%$ to $2 \%$, the quality of the preschool education was at risk of not meeting the expectations of Vietnamese education. The developing conditions and the socio-economic situation were increasing, so the parents' demand was also higher. However, the number of PT was still insufficient, so early childhood education was not possible to meet society's demand. As a result, the effectiveness of early childhood education was not ensured. Therefore, it was easy to view that the height of the Vietnamese children was limited in comparison with the other Asian countries [24]. The children attending to kindergarten were still sometimes violated (in both groups of the public and private kindergartens) [25], and this might still be in danger of continuing to happen. If examining the roadmap, with the current redundant situation of the number of the teachers, after one year or a year and a half of training, it would be necessary to have a specific training process for a degree, instead of training massively. Specifically, with the capacity and internal resources for formal preschool education with about 5,000 to 8,000 PT every year, for three consecutive years, the number of the trained early childhood teachers will be able to meet the practical demand if there are no sudden changes with the forecast of the ratio of gaining the second degree ranging from $70 \%$ to $90 \%$ after training.

The reason why the number of PT increased in transferring their careers was the issue that demands to be explained and found the solutions to intervention. PT's 
work was severe and complicated [26-28]. Their best effort for the careers, their investment in the professional skills of almost all the Vietnamese PT were under the expectation of excellent achievements to motivate them [29-30]. In reality, the policies and working conditions for the PT were lower than the other education levels [31]. This was one of the causes affecting the general situation that the number of PT tended to decrease as the reflected result.

With the results of the number of undergraduate student input and output in preschool education, it was found that the sharp fluctuations in the number of student output could be a consequence of the biological population increase in the previous years, increasing the number of school-age children. Therefore, the need for schools and the new teachers also increased suddenly, especially the children of the preschool age. However, it was also the reason that it was impossible to measure all the real and unreal demand, which made an absolute difference in the forecast of the number of school-age children. As a result, the identification of the enrollment criteria for admission, as well as the output training, was exceeded. This led to the redundancy of PT. Therefore, it is forced to reduce enrollment and training in the following years.

In 2021-2022, a large number of children attending preschool could lead to a shortage of teachers. This showed that the multidimensional survey on many criteria of the geographic areas gathering the number of the children attending kindergarten/preschool or the development of the children attending school in the industrial parks and the manufacturing zones is starting to happen in Vietnam in the past years [32-33]. Along with the gender bases [34], it was necessary to mobilize assistance of the educational forces in managing and coordinating the allocation of human resources as well as investing in infrastructure expansion to meet the demand of the preschool education and the number of the preschool children attending to school in practice.

In a 5-year frame, the percentage of the investigated PT increased or decreased erratically, but the increasing trend was more than the ratio of the retired teachers. Moreover, when comparing this rate to the rate of children attending school in this 5-year frame, the number of children decreased significantly. So, the situation of the PT recruitment was the problem with the following directions: Firstly, this recruitment was not based on the actual demand in practice; Secondly, the data on the situation of the PT and human resource development in education was not effectively exploited as the basis; Thirdly, the PT recruitment has not been based on the relevant conditions. Indeed, the national data could have a general effect, and the risk that the recruitment could be appropriate for some provinces was the obligatory option. However, it was not the reason that its influence dominated nationally. It could be concluded that the issue of the PT increasement or additional recruitment had not been established on specific bases, and this responsibility necessarily needed to be addressed based on the education sector's functions and tasks in the future.

With the results in the individual components of the PT projection, it was discovered that the Vietnamese EP needed to ensure. Firstly, the rate of undergraduate preschool education students' employment after graduation. Secondly, the rate of the PT continuing to follow their jobs after one year, five years. Thirdly, the proportion of the private childcare groups established. Fourthly, the number of independent childcare groups (it is not possible to follow the number of children/teachers). Indeed, in recent years, the number of non-public and private preschools has developed actively in Vietnam [35]. It could be said that the number of independent and private childcare institutions was much higher than that of public kindergarten ones [36]. This affected the reallocation of the today PT workforce because the non-public and private kindergartens paid the teachers a higher salary than the public ones. The working conditions and environment were much more invested, which led to attracting more teachers [37], this also raised many ethical issues [38], as well as the legal aspect [39].

Finally, with the results in terms of the PT's training in the period 2017 - 2027, it was found that the number of PT through the years decreased significantly. From the above data, there were two parallel options to consider: increasing the PT training targets or at least keeping stable the preschool education targets in the frequent targets of the pedagogical universities and colleges. Alternatively, the second option was that developing the internal resources in the preschool education sector as well as the education sector.

\section{Conclusions}

After analyzing the collected data, it could be concluded that: Firstly, at the preschool level, the number of the working teachers tended to increase gradually throughout each academic year and tended to increase more than the percentage of the retired teachers and the teachers who transferred their jobs. However, this slight increase could not guarantee a shortage of PT resources, but it ensured the number of preschool children attending school. This could be considered a quite positive change in Vietnam's education sector. Second, for ten consecutive years from 2017 to 2027, there would be a shortage of from more than 12,000 teachers to the highest of 25,000 teachers. The projected year, with the highest lack of preschool teachers, was the academic year 2020-2021 with 24,820 teachers. This clearly showed that the need for the PT, in reality, was still lacking, and the projection chain showed that without practical solutions, there would be a risk of acute and long-lasting shortage in 2022-2023. Thirdly, to ensure the sustainable development of education, it was necessary to give concern to the EP as a long-term strategy and vision, 
in which the education of PT needed to ensure its quality at the first level of education in the national education system to establish the basis for developing education at higher levels. The results prove the feasibility of applying the extrapolation method to project the education for a country within ten years with absolute validity and reliability. Also, the combination of the extrapolation method with comparative data from national agencies and organizations on a country's population brings more excellent reliability, helping to reinforce this method. EP is the job that needs more attention, priority, and specific plans to ensure the steady educational development conditions, not only in Vietnam but also in other Asian countries with the same socio-cultural characteristics and education. The limit of the study is project under the standard conditions. Population variation (number of children attending school) is projected based on the differences in the Vietnamese geography and cultural birth conception. The variation in the number of PT is projected on the conditions of input output standards of pedagogical students, conditions of employment policy (career transfer, retirement) without considering other conditions such as leave of absence, deaths, strategic plans, and terminations. The researcher expects other studies on EP in Vietnam, as well as developing countries in Asia which will focus on this limit to develop and expand the research.

\section{REFERENCES}

[1] Ministry of Education and Training. (2012). Chien luoc phat trien giao duc 2011 - 2020 (ban hanh kem theo Quyet dinh so 711/QD-TTg ngay 13 thang 6 nam 2012 cua Thu tuong Chinh phu) [Education Development Strategy 2011-2020 (Issued together with Decision No. 711 / QD -TTg of June $13^{\text {th }}, 2012$ of the Prime Minister]. Hanoi, Vietnam: Government Publishing Service.

[2] Broadfoot, P. (1996). Education, assessment, and society: a sociological analysis (Vol. 68). Buckingham: Open University Press.

[3] Campbell, D. M., Melenyzer, B. J., Nettles, D. H., \& Wyman Jr, R. M. (1999). Portfolio and performance assessment in teacher education. USA: Center for Teaching and Technology - Book Library.

[4] Pecheone, R. L., \& Chung, R. R. (2006). Evidence in teacher education: The performance assessment for California teachers (PACT). Journal of Teacher Education, 57(1), 22-36.

[5] Do, C. (1984). Du bao nhu cau can bo chuyen mon Viet Nam den nam 2000 [forecast of demand for Vietnamese professional officials till 2000]. Vietnam: University and high school research institutes.

[6] Barnett, W. S. et al. (2010). The State of Preschool 2010: State Preschool Yearbook. USA: National Institute for Early Education Research.
[7] Blossfeld, H. P., Kulic, N., Skopek, J., \& Triventi, M. (Eds.). (2017). Childcare, early education and social inequality: An international perspective. USA: Edward Elgar Publishing.

[8] Friedman-Krauss, A. H., et al. (2018). The State of Preschool 2017: State Preschool Yearbook. USA: National Institute for Early Education Research.

[9] Ministry of Education and Training. (2013b). Quyet dinh 1215/QD/BGDDT ngay 4 thang 4 nam 2013 ban hanh Chuong trinh hanh dong cua nganh giao duc thuc hien chien luoc phat trien giao duc Viet Nam 2011 - 2020 [Decision 1215/QĐ /-BGDĐT April 4 ${ }^{\text {th }}, 2013$ promulgating the Action Program of the education sector to implement the Vietnam Education Development Strategy 2011-2020]. Hanoi, Vietnam: Government Publishing Service.

[10] Ministry of Education and Training. (2013a). Chuong trinh hanh dong cua nganh giao duc thuc hien chien luoc phat trien giao duc Viet Nam 2011 - 2020 [The education sector's action program implements Vietnam's education development strategy 2011-2020]. Hanoi, Vietnam: Government Publishing Service.

[11] Kc, S., Barakat, B., Goujon, A., Skirbekk, V., Sanderson, W., \& Lutz, W. (2010). Projection of populations by level of educational attainment, age, and sex for 120 countries for 2005-2050. Demographic Research, 22, 383-472.

[12] Lim, J. H., Kwon, O. S., Song, K. B., \& Park, J. D. (2013, May). Short-term load forecasting for educational buildings with temperature correlation. In 4th International Conference on Power Engineering, Energy and Electrical Drives (pp. 405-408). IEEE.

[13] Markova, S. M., Sedhyh, E. P., \& Tsyplakova, S. A. (2014). Upcoming trends of educational systems development in present-day conditions. Life Science Journal, 11(11s), 489-493.

[14] McMeen, G. R. (1987). The role of forecasting in educational technology. Educational Technology, 27(3), 36-39.

[15] Hudson, B., \& Bruno, J. (1978). Educational Forecasting Methodologies: State of the Art, Trends, and Highlights.

[16] Blaug, M. (1967). Approaches to educational planning. The economic journal, 262-287.

[17] Weaver, W. T. (1971). The Delphi forecasting method. The Phi Delta Kappan, 52(5), 267-271.

[18] Zahedi, F. (1990). A method for quantitative evaluation of expert systems. European Journal of Operational Research, 48(1), 136-147.

[19] Makridakis, S., Andersen, A., Carbone, R., Fildes, R., Hibon, M., Lewandowski, R., ... \& Winkler, R. (1982). The accuracy of extrapolation (time series) methods: Results of a forecasting competition. Journal of forecasting, 1(2), 111-153.

[20] Chatfield, C. (1988). What is the 'best' method of forecasting? Journal of Applied Statistics, 15(1), 19-38.

[21] Armstrong, J. S. (1984). Forecasting by extrapolation: Conclusions from 25 years of research. Interfaces, 14(6), 52-66. 
[22] Erb, C. B., Harvey, C. R., \& Viskanta, T. E. (1994). Forecasting international equity correlations. Financial analysts journal, 50(6), 32-45.

[23] Jain, A., Srinivas, E., \& Rauta, R. (2009, December). Short term load forecasting using fuzzy adaptive inference and similarity. In 2009 World Congress on Nature \& Biologically Inspired Computing (NaBIC) (pp. 1743-1748). IEEE.

[24] Nguyen, K. H. (1996). Phat trien dan so va phat trien giao duc o thanh pho Ho Chi Minh [Population development and educational development in Ho Chi Minh City]. (Unpublished Department of Education and Training research). Ho Chi Minh City University of Education, Ho Chi Minh City, Vietnam.

[25] Hoang, V. N., Nghiem, S., \& Vu, X. B. (2019). Stunting and academic achievement among Vietnamese children: new evidence from the young lives survey. Applied Economics, 51(18), 2001-2009.

[26] Son, H. V. (2016). The reality, causes and some solutions to overcome the school violence in Can Tho city. (Unpublished city-level scientific research topics, code CT2016.01). Ho Chi Minh City University of Education, Ho Chi Minh City, Vietnam.

[27] Brown, E. L., Vesely, C. K., Mahatmya, D., \& Visconti, K. J. (2018). Emotions matter: the moderating role of emotional labour on preschool teacher and children interactions. Early Child Development and Care, 188(12), 1773-1787.

[28] Hu, B. Y., Fan, X., Yang, Y., \& Neitzel, J. (2017). Chinese preschool teachers' knowledge and practice of teacher-child interactions: The mediating role of teachers' beliefs about children. Teaching and Teacher Education, 63, 137-147.

[29] Kontos, S. (1999). Preschool teachers' talk, roles, and activity settings during free play. Early Childhood Research Quarterly, 14(3), 363-382.

[30] Lavoie, C., \& Benson, C. (2011). Drawing-voice as a methodological tool for understanding teachers' concerns in a pilot Hmong-Vietnamese bilingual education programme in Vietnam. Language, Culture and Curriculum, 24(3), 269-286.

[31] Phan, N. T. T., \& Locke, T. (2016). Vietnamese teachers' self-efficacy in teaching English as a Foreign Language: Does culture matter? English Teaching: Practice \& Critique, 15(1), 105-128.

[32] Son, H. V. (2012). Phat trien nguon nhan luc trong giao duc, danh cho hoc vien Cao hoc Quan ly Giao duc [Human resource development in education, for master student of education administration]. (Unpublished teaching materials). Ho Chi Minh City University of Education, Vietnam.

[33] Linh, T. G., \& Thao, N. T. P. (2011). Social protection for rural-urban migrants in Vietnam: current situation, challenges and opportunities. The UK: CSP Research Report 08.

[34] Pham, L. T. L., Vu, L. H., \& Schelling, E. (2012). Health services for reproductive tract infections among female migrant workers in industrial zones in Ha Noi, Viet Nam: an in-depth assessment. Reproductive health, 9(1), 4.
[35] Son, H. V., Vu, G. T, Long, L. D., Hong, N. K. \& Huan, N. T. (2019). Forecasting the Number of Children and Students Attending to School in Vietnam - The Interest in Gender Difference. Journal of Social Sciences Research, Vol 5 (7), 1176-1183. doi: doi.org/10.32861/jssr.57.1176.1183.

[36] Vietnamese Government. (2012). Chien luoc phat trien giao duc 2011 - 2020, ban hanh kem theo Quyet dinh so 711/QD-TTg, Ha Noi [Education Development Strategy 2011 - 2020, issued together with Decision No. 711 / QD-TTg, Hanoi]. Vietnam: Government Publishing Service.

[37] Lan, H. T. (2018, August). Management of pedagogical capacity building activities for preschool teachers in Vietnam. In Educational Administration Innovation for Sustainable Development: Proceedings of the International Conference on Research of Educational Administration and Management (ICREAM 2017), October 17, 2017, Bandung, Indonesia (p. 197). CRC Press.

[38] Dan Tri Magazine. (2013). Chat luong giao duc mam non thieu va yeu: Giai quyet the nao? [The quality of preschool education is lacking and weak: How to solve it?]. Retrivied from:https://dantri.com.vn/giao-duc-khuyen-hoc/chat-luon g-giao-duc-mam-non-thieu-va-yeu-giai-quyet-the-nao-137 4534191.htm.

[39] Phuong, D. H. (2017). Thuc trang va giai phap nang cao chat luong giao duc mam non Vietnam trong thoi ki hoi nhap quoc te [situation and solutions to improve the quality of Vietnam early childhood education in the period of international integration]. Vietnamese Education Journal, $12,130-132$.

[40] Phuong, D. H. (2012). Doi dieu suy nghi ve giao duc mam non thoi ki hoi nhap quoc te [Something to think about early childhood education in the period of international integration]. Unpublished conference proceeding of the model of preschool teachers' personality in the period of international integration. Preschool education Department, Hanoi Education University. Pp.103-105. 